\title{
Reseña \\ Francisco López Segrera. América Latina: Crisis del posneoliberalismo y ascenso de la nueva derecha. Buenos Aires: CLACSO. Libro digital. 143 págs. 2016.
}

Marina Campusano*

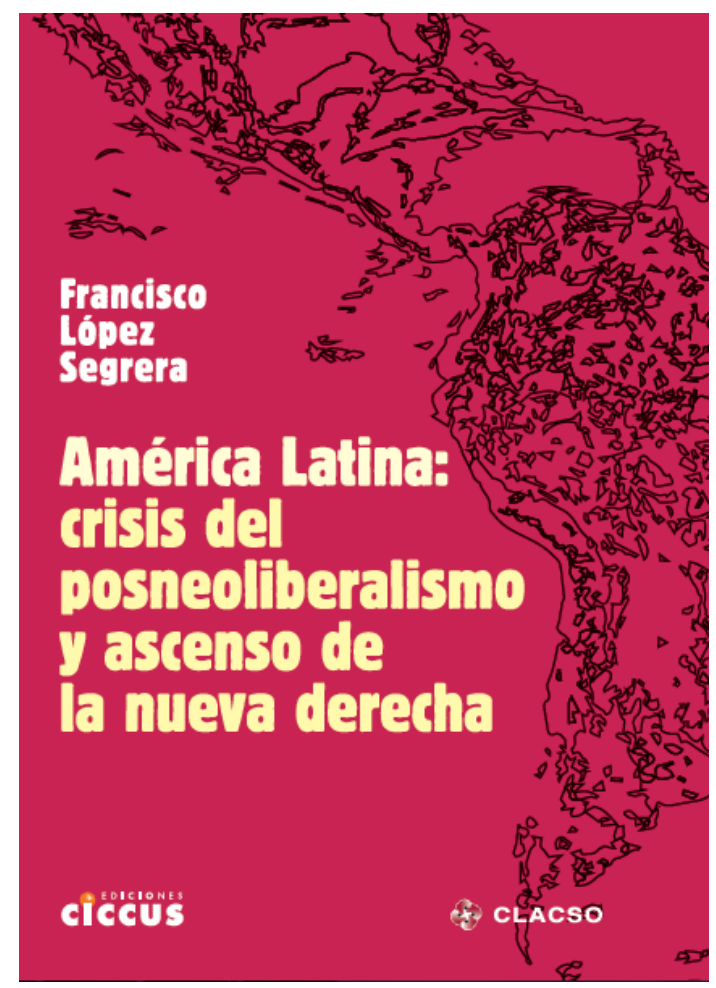

\section{Disponible en:}

http://www.clacso.org.ar/libreria-latinoamericana/contador/sumar_pdf.php?id_libro=1175

\footnotetext{
* Licenciada en Comunicación Social-Becaria doctoral Conicet-Centro de Estudios Sociales UNNE.

Correo electrónico: marinacampusa@gmail.com.
} 
Centrado en las transformaciones del escenario político latinoamericano que evidencian un cambio de ciclo y lo muestran en un viraje hacia la derecha, Francisco López Segrera nos propone, en este nuevo libro digital de CLACSO, recorrer los procesos que atravesaron los gobiernos posneoliberales para comprender el ascenso actual de grupos que identifica como representativos de "nuevas derechas". Se detendrá así, a lo largo de los cinco capítulos que componen el libro, en los principales rasgos que los caracterizan para ayudarnos a rearmar el escenario político del continente y sus futuras proyecciones.

Es importante destacar la trayectoria del autor, quien, más allá de su formación en Estudios Latinoamericanos e Hispánicos, ha estado involucrado en cargos que implicaron tareas en la diplomacia cubana, como así también en la UNESCO, abocado a reflexionar en torno a la tarea y responsabilidad de las ciencias sociales para América Latina y el Caribe (ALC). Esas vivencias resalta el autor como presentes y necesarias al momento de encarar el proyecto del libro.

En el Capítulo 1, Tipología de América Latina y el Caribe e indicadores clave, el autor recorre los procesos políticos y económicos de los países de la región haciendo un repaso por las políticas que acompañaron las décadas de los 80 y los 90, con el objetivo de centrar la mirada en los factores de desarrollo de las estructuras productivas eficientes. De ello resulta una caracterización que deja en evidencia la dependencia de las economías de ALC a las "commodities consensus", es decir a la exportación de las materias primas como factor central del crecimiento de sus economías. En este sentido, propone una tipología de acuerdo al tipo de modelo y medidas que impulsan los gobiernos distinguiendo, por un lado, aquellos que favorecen reformas neoliberales.

En este apartado resulta interesante la inclusión de los datos referidos a los índices de crecimiento, desempleo, pobreza y desigualdad, publicados por organismos como la Comisión Económica para América Latina y el Caribe (CEPAL), la Organización Internacional del Trabajo (OIT) y el Banco Mundial, para marcar los contrastes del periodo 2003-2015 con los años anteriores. Por ejemplo, destaca que para 2013 el porcentaje de pobres que había en la región se había reducido a 27,9\% y el de indigentes a 11,5\% en comparación con las cifras de 1980 que registraba 40,5\% de pobres y $18,6 \%$ de ellos en condición de indigentes. No obstante, el autor remarca que ALC continúa siendo la región más desigual del mundo.

Sobre este aspecto, López Segrera resalta que la reducción de los niveles de pobreza y desempleo, así como el crecimiento que evidenció el continente, está vinculado con las políticas sociales de los gobiernos progresistas de corte posneoliberal. Principalmente a aquellas medidas económicas integracionistas desarrolladas por el 
conjunto de los países donde cobran relevancia organismos regionales como la CELAC, MERCOSUR, ALBA; asimismo, subraya la dinamización de algunos esquemas integracionistas con petróleo a precios preferenciales y créditos blandos por parte de Venezuela, la importante entrada de divisas procedente de las remesas de los emigrantes, la inversión extranjera y el turismo.

Asimismo, un factor que el autor reconoce como fundamental para el crecimiento es el alza de los precios de las materias primas en el mercado mundial y la demanda de estos productos por los países emergentes como China que favoreció a ALC durante la etapa 2003-2012. Sin embargo, señala que ese ciclo se ha desacelerado a partir de 2013-2014, debido al descenso de los precios de las materias, al igual que el del petróleo. Este factor es central para poder comprender el escenario difícil que tuvieron que afrontar los gobiernos posneoliberales para seguir financiando sus políticas sociales inclusivas y asociadas a ello su posterior crisis y el ascenso de la nueva derecha.

Situación actual y perspectivas del posneoliberalismo lleva por título el Capítulo 2, donde nos propone detenernos en los principales gobiernos de ese tipo para analizar su desarrollo, las condiciones que marcaron el abandono del neoliberalismo y las características comunes que nos permitan reconocerlo como bloque regional a modo de indagar en las causas de sus posteriores crisis.

Es interesante destacar la tipología que brinda sobre los estilos de izquierda que reconoce en ALC entre 1925 y 2016, distinguiendo de 1925 a 1959 la "izquierda marxista y la populista"; de 1959 a 1990, la "izquierda guerrillera"; y de 1990 al 2016, la "izquierda nacional-popular y pos-neoliberal". De esta manera, propone el recorrido histórico por la evolución de estos modelos, centrándose en las formas de surgimiento en cada país del último, iniciado con la llegada a la presidencia de Hugo Chávez Frías en Venezuela, en 1998.

Este recorrido permite adentrarnos en los puntos de encuentro de tales modelos para analizar críticamente los motivos de sus crisis, el autor se pregunta por el fin del ciclo de los gobiernos de izquierda y llama la atención sobre el mantenimiento del modelo productivo extractivista que, acompañado por una coyuntura de altos precios del petróleo y de las materias primas, sirvió para financiar las políticas sociales, pero no para profundizar medidas con vistas a apuntalar la industrialización o una mayor redistribución del ingreso que permita construir un modelo con mayor independencia. Otro problema central que observa y es necesario rescatarlo es la incapacidad de estos gobiernos para impulsar una nueva cultura revolucionaria, una nueva conciencia y una nueva ética que se haya podido desarrollar a la par de las políticas sociales que favorecieron a los sectores más desfavorecidos, López Segrera sentencia que si la batalla de ideas se pierde, reaparece la hegemonía de derecha y, en ese contexto, son los propios "beneficiarios" quienes se pasan a ese sector. 
Estos aspectos, más otros señalamientos que incorpora el autor, son claves al momento de comprender el ascenso de lo que denomina como una nueva derecha y la encrucijada en la que se encuentran los gobiernos de Bolivia y Ecuador, por ejemplo, para mantenerse en un escenario que se les presenta más que desalentador, pero no irreversible.

Sin duda, la "novedad" de los grupos en ascenso es uno de los principales ejes del trabajo y el Capítulo 3, Ascenso de la Nueva Derecha, en el que se plantea desandar los rasgos que caracterizan esta nueva derecha en comparación con las anteriores. En este sentido, el autor identifica históricamente tres tipos: de 1964 a 1985 predominó la "dictatorial"; de 1985 al 2000, la "neoliberal", y señala que desde el año 2000 ha emergido una "nueva".

La pregunta que guía este apartado se centra en tratar de explicar por qué si los gobiernos posneoliberales han reducido un porcentaje elevado de la pobreza, la marginalidad y la exclusión social, se evidencian sus fracasos y la emergencia de nuevos grupos en el poder. De esta manera, el autor se adentra en la caracterización de la novedad de los sectores de derecha que ocupan tanto los espacios de la oposición (Venezuela, Brasil, Ecuador y Bolivia) como aquellos que se encuentran en el gobierno (México, Colombia, Perú y Argentina).

Es así que logra agrupar una serie de características transversales a estos grupos, de las que sobresalen: su discurso moderado, el impulso de programas económicos promercado $y$, en ese sentido, presentan una marcada tendencia a priorizar las relaciones bilaterales con EE.UU. en desmedro del desmantelamiento de los acuerdos de integración regionales (MERCOSUR, CELAC, ALBA, UNASUR). Uno de los aspectos clave que señala es que han sabido capitalizar el descontento y decepción de las clases medias tradicionales y emergentes, de sectores de las clases populares y de los indígenas ante el alza del costo de la vida, la inflación, los impuestos y la inseguridad, al igual que el creciente rechazo de "las políticas asistencialistas que no los sacan de la pobreza, ni muchas veces les garantizan un empleo, y por otro, de que pese a lo recibido de las políticas sociales de los gobiernos posneoliberales, esto no implica que sean leales a ellos en el mediano plazo, en especial cuando ya no reciben dádivas y ven sus salarios reducidos al mínimo por la inflación" (2016, p. 80).

Los factores del proceso de integración económica regional en ALC son el eje del Capítulo 4 denominado Geopolítica Imperial vs Integración latinoamericana, en él López Segrera identifica y describe, a través de un recorrido histórico, tres etapas que agrupan los intentos de ruptura con un modelo basado en la dependencia económica y caracterizado por la imposición de las reglas del mercado por sobre la figura de los estados, la desregulación, la privatización y la liberalización comercial marcando la subordinación de los países latinoamericanos. Cada uno de ellos reafirmaba el carácter estratégico de ALC y, por lo tanto, la necesidad de su control no solo económico. 
Este recorrido permite contrastar y dimensionar las medidas llevadas adelante por los gobiernos posneoliberales y las condiciones en que lo hicieron, otorgando al Estado un rol central en la gestión de la economía. En este sentido, resulta interesante el análisis que realiza enfatizando que estos gobiernos no solo tuvieron la voluntad política, sino que también contaron a su favor con los recursos que les permitieron desarrollar propuestas regionales de integración, como la Alianza Bolivariana para los Pueblos de Nuestra América (ALBA) en 2004, la Unión de Naciones Suramericanas (UNASUR) en 2008 y la Comunidad de Estados Latinoamericanos y Caribeños (CELAC) en 2010.

Es por ello que durante el periodo la conformación de tales organismos fue clave para echar por tierra la decisión de impulsar el desarrollo dejando por fuera a actores extraregionales -sobre todo EE.UU.-, sin embargo, el autor resalta el papel que tuvieron en este periodo el incremento de la presencia de otros bloques económicos (BRICS, G20).

Ese escenario, sin dudas, hoy está en crisis. López Segrera retoma como señal de la misma los dichos del ex ministro de Hacienda y Finanzas de Argentina, Alfonso PratGay, quien expresó durante su llegada a la cartera las intenciones de "refundar el Mercosur". Al respecto, el autor advierte sobre el sentido que podría llegar a adquirir esa refundación, y teniendo en cuenta lo expuesto en el libro, claramente se encauza hacia la apertura de "espacios para acuerdos bilaterales de libre comercio con los EE.UU., rebajar el perfil del Mercosur y fortalecer la Alianza del Pacífico" (2016, p. 110).

Finalmente en el Capítulo 5, Escenarios 2016-2030, el autor desarrolla una serie de proyecciones para ALC de manera regional y luego por países, resultando interesante en este apartado la puesta en situación y reconstrucción del contexto internacional, retomando las variables formuladas por la CEPAL como: situación de la economía mundial; Producto Bruto Interno (PIB) y PIB per cápita; inversión extranjera directa (IED); precios del petróleo y las materias primas; inflación y salarios; crecimiento de la población; porcentaje de pobreza e indigencia; índice de desempleo; coeficiente GINI y acceso a los distintos niveles de educación, las cuales retoma para poder realizar sus apuestas.

Enmarcados en un contexto que no se reduce a nuestro continente, sino que el ascenso de tales grupos está configurando el escenario mundial, el libro viene a contribuir a las discusiones en torno a desde qué posiciones pensar y revisar los caminos abiertos por los gobiernos posneoliberales, sus errores y obstáculos, y principalmente los desafíos actuales que demandan con urgencia mucha creatividad política para trazar nuevas estrategias. Sin duda, los abordajes presentados nos permiten contextualizar y mirar a ALC históricamente en su devenir para poder analizar sus complejidades desde una mirada más integral.

A modo de cierre, me permito recuperar las palabras del vicepresidente de Bolivia, Aldo García Linera, a quien retoma el autor, para describir el momento actual de una 
manera más alentadora: "la revolución es un proceso por oleadas (...) y estamos ante el fin de la primera oleada y está viniendo el repliegue (...) pero más pronto que tarde habrá una segunda oleada, y lo que tenemos que hacer es prepararnos, debatiendo qué cosas hicimos mal en la primera oleada, dónde cometimos errores, qué nos faltó por hacer (...) Tocan tiempos difíciles, pero para un revolucionario los tiempos difíciles es su aire (...) y el tiempo histórico está de nuestro lado (...) ya que ellos no tienen alternativa (...) Nosotros somos el futuro, somos la esperanza" (2016, p. 72). 